\title{
Student and Faculty Choices that Widen the Experience Gap
}

\author{
Lecia J. Barker \\ University of Colorado, USA \\ Elizabeth R. Jessup \\ University of Colorado, USA
}

\section{INTRODUCTION}

A major teaching challenge for higher education faculty is students' wide differences with respect to experience or knowledge with the subject matter or skill set of a class. In computing education research, this is often referred to as the "experience gap." Research shows that the experience gap contributes to the low participation of women in professional information technology (IT) careers. Women are significantly more likely to enter college-level IT courses with little or no computer programming experience than are their male peers (College Board, 2004). Yet, programming experience is positively associated with success, especially in introductory classes (Taylor \& Mounfield, 1994; Bunderson \& Christensen, 1995; Brown, 1997; Margolis \& Fisher, 2002), and low grades are positively associated with attrition from the major (Strenta, Rogers, Russell, Matier, \& Scott, 1994). When women receive low grades due to inexperience, they may be more likely than males to lose confidence and leave the major (Cohoon \& Aspray, in press).

Another type of experience gap becomes evident in cross-disciplinary teams, where students encounter others whose areas of expertise and knowledge are substantially different, often to the point where students have difficulty understanding each other. According to IEEE Computer Society/ACM Computing Curricula Task force, "Computing education is also affected by changes in the cultural and sociological context in which it occurs" (IEEE and ACM Joint Task Force, 2001, p. 10). For this reason, both Computing Curricula 1991 and 2001 strongly recommend the integration of experiences and opportunities for student understanding of real-world applications and the people who need them. Courses that provide opportunities for collaborative and interdisciplinary learning are also often recommended to increase retention of women in science, technology, engineering and mathematics (STEM) courses in general (Agogino \& Linn, 1992; Felder, Felder, Mauney, Hamrin, \& Dietz, 1995) and in computing, in particular (McDowell, Werner, Bullock, \& Fernald, 2003; Barker, Garvin-Doxas, \& Roberts, 2005). Yet, collaborative learning and, in particular, projectbased courses, must be carefully planned and managed for students to have similar learning outcomes. In this article, we demonstrate how students' choices can reinforce and even widen differences in experience and reduce their ability to develop crossdisciplinary understandings.

\section{BACKGROUND}

Unlike most assignments in the computer science curriculum, team projects are too complex to be completed by a single student. Team projects involve building practical solutions to substantial problems, requiring that students evaluate alternative designs in terms of cost, performance and so forth. Team members must determine what they will deliver and how - and how to distribute the work. The process of bringing idea to product is part of what gives students the professional experience.

In their review of projects within the traditional computer science curriculum, Fincher, Petre and Clark (2001) characterize project work as a way for students to "show their stuff." To be successful in project work, they note, students must demonstrate mastery of a diverse collection of technical skills acquired over terms or years of study. The authors believe that the most diverse project teams are 
Student and Faculty Choices that Widen the Experience Gap

formed by splitting up "affinity groups" (friendships or cultural groups) and creating a mix of interpersonal and technical abilities. Such teams may increase the potential for peer learning. Teams formed from computer science majors from a single institution, however, are quite likely limited in their diversity of knowledge and may not bring students professional experience in interacting with people substantially different from themselves.

More innovative IT programs present the possibility of more heterogeneous project teams with students of different majors. Ideally, the tasks performed by such groups require that all students share their knowledge and expertise as well as their questions and uncertainties in ways that lead to peer learning (Tinzmann, Jones, Fennimore, Bakker, Fine \& Pierce, 1990). However, this ideal assumes that students take equal responsibility for the roles of teacher and student, and that tasks focus on learning through dialog and hands-on activities (Johnson \& Johnson, 1994). Knowledge asymmetry, when one group member is more expert on a topic than another, is to be encouraged and expected in group projects because it creates an opportunity for peer tutoring, benefiting both the more expert and less expert students. Further, in successful learning groups, students alternate between different types of roles and communication: those involving peer tutoring in which the roles of "teacher" and "student" are clear and well defined, and collaborative sequences where students work together in free discussion to create knowledge and understanding with no clear role differences (Haller, Gallagher, Weldon \& Felder, 2000).

Yet, simply putting students in project groups does not automatically lead to improved or crossdisciplinary learning through the processes described above, because students' understanding of collaboration may be quite limited by lack of experience and even a belief that collaboration is cheating (Barker, Garvin-Doxas, \& Jackson, 2002). Instead, they often divide the work, taking on the part most consistent with their "comfort zone" or most expedient for finishing the project. When students have different levels or areas of knowledge, students of both sexes can take on gendered roles or roles based on experience. Further, students may accept less learning in the interest of getting a product and "showing their stuff." The case study we present below demonstrates how students take on roles in project groups.

\section{WIDENING THE EXPERIENCE GAP}

This case study describes one project team from Technology for Community ( $\mathrm{T}$ for $\mathrm{C}$ ), an undergraduate computer science course taught at the University of Colorado at Boulder. In $\mathrm{T}$ for $\mathrm{C}$, student teams work with local community service agencies, building computational solutions to problems confronting those agencies. The course has no prerequisites, and participants have diverse backgrounds in terms of educational experience, major and expertise with technology. Although few computer science majors are female, this course has consistently attracted a large proportion of female students. Most of those women, however, come from the technology, arts and media (TAM) certificate program.

The TAM certificate program, open to all undergraduates, requires that students take six courses, three of which require hands-on development in project teams. Students acquire expertise with highend software packages (e.g., Flash, Photoshop) and some HTML programming, with the goal of designing and producing multimedia materials both for selfexpression and to serve clients. Programming courses (e.g., Java) are optional, and most students do not take them. Three of the courses are focused on historical issues related to information and communication technologies, communication theory, implications of media for society and the like. TAM student enrollment is consistently more than half women.

In each $\mathrm{T}$ for $\mathrm{C}$ project, students are expected to acquire new skills and experience. While most students improve their abilities to interact with a real client with real needs and to design for and test with real users, not all succeed in enhancing their technical skills. Instead, students, succumbing to real or imagined time constraints, fall into their comfort zones. Because of the multidisciplinary nature of the course, students arrive with different levels of technical, communication and design experience. Learning to work across disciplines within project teams is a new experience for many of the students, and 
different project teams succeed to different degrees in responding to that diversity. The case study below illustrates how one student team responds to both types of experience gap.

The case is based on data collected in an ethnographic study conducted by the first author. Ethnography is a qualitative research method that focuses on articulating the shared-yet often unspokenrules, beliefs and values produced and made visible in everyday communicative interaction. The second author developed the $\mathrm{T}$ for $\mathrm{C}$ course and has taught it for four semesters. The case study is based on 35 hours of observation of $\mathrm{T}$ for $\mathrm{C}$, a focus group interview with 10 TAM students (including both of the females presented below) and experiences of the instructor.

On one $\mathrm{T}$ for $\mathrm{C}$ team, Jane (studying TAM, Spanish and education), Maria (studying TAM, journalism and molecular biology) and John (studying computer science) were tasked with creating an educational Web site for middle school children in a bilingual charter school. They attended a workshop including the school principal, conducted interviews with her and visited the school to understand teachers' and children's needs. Building the site required design and content development and HTML coding. Once the parameters of the project were defined, the students decided which of them would carry out which tasks. They then began their work on those tasks, individually or jointly.

All three students were bright, creative and accomplished in their chosen majors, yet early in the project, the differences in those majors led to a severe breakdown in their interactions. The two women complained to the instructor that John was uncommunicative, not available to meet and a poor contributor. The instructor was surprised: She knew John from two previous courses to be conscientious, friendly and well liked by peers. She nonetheless called John in for a discussion about his work in T for C. As it turned out, John was unaware of the dissatisfaction of his teammates. He was working hard on his parts of the project and checking in with Maria and Jane regularly by e-mail. The conflict turned out to be a problem of culture. John was accustomed to solitary, late-night work in the computer lab while the women were expecting regular, in-person project team meetings. The instructor intervened, making John aware of the need for such meetings while letting Jane and Maria know that the meetings would have to take place late in the day to accommodate John's work schedule. With those simple ground rules in place, the students quickly found common ground in their project, and they came to see that everyone was making good contributions. For the remainder of the semester, theirs was a very successful project team, and lasting friendships among the three resulted.

While Maria, Jane and John ultimately developed a high-quality site for the school, a closer look at their interactions revealed some troubling features with respect to the experience gap. In particular, the students split up the work along disciplinary (perhaps gendered) lines, with Jane and Maria making most design and content decisions, and John doing the HTML coding. It is easy to see why Jane, as a Spanish major and pre-service teacher, would be especially good at providing content for this project. However, John's and Maria's roles were not quite so straightforward and were negotiated through many interactions. For example, at one point, the three were discussing icons and images. As Maria explained to John at length why she saw an image as particularly good, he repeatedly expressed agreement with her, but she did not acknowledge it. It was as if she could not register that he might possibly know enough about images to agree. On another occasion, the team was having a technical problem saving an image as a GIF file. Jane's opinion overrode John's suggestion for solving the problem on the implied basis that she had a better eye for image quality; his solution, she said, would diminish that quality. Maria's view of John's potential contributions to the project was limited, and limiting to John.

Yet John was clearly conscious of design and thoughtful about content and users' needs. For example, when deciding on the approach to helping children find the help they need with research, the purpose of the site, it was his idea to use questions ("Do you want to find a book?") rather than headings ("Research"), because as he said, "kids don't think in those terms." During whole-class discussion about intuitive tasks, John pointed out that in the Macintosh interface, dragging the floppy disk icon to the trashcan to eject can make people afraid that they're somehow deleting files on the disk. In fact, throughout the project, we docu- 
mented many of John's insightful comments about the site's appearance and content. But with his ideas and knowledge repeatedly ignored or brushed aside, John learned implicitly that design and content were not to be his domain. Jane and Maria seemed to have staked out content and design as their territory. This move may appear to be gendered, yet it was also made by virtue of their unarticulated beliefs about what kinds contributions a computer science major can make.

During the focus group interview, TAM students discussed the image of a computer science major. Maria said, "I've taken a $\mathrm{C}++$ programming class and there's really no creativity there." It is not clear whether Jane shared this belief (several other students objected to this), but Maria's inability to see computer science as "creative" may have impeded her ability to "hear" John's design ideas. Her initial beliefs and the implicit messages embedded in many interactions were likely a factor in John's relegation to HTML coding - at the expense of his obvious desire to participate in design decisions. Also interesting is the revelation that although Maria adopted the role of content and design, she actually had substantial programming experience. When we asked Maria why she and Jane did mainly content and design and John the coding, she narrowly characterized John's contribution, explaining that he was a fast programmer, that she and Jane had made a similar Web site before and that they were under time pressure (more on this later). In spite of her own ability to function in any of the three roles, Maria was unable to see John, a CS major, as functional in the roles of content and design. In fact, all three of those students could have provided more input or support in all three knowledge domains.

$\mathrm{T}$ for $\mathrm{C}$ is intended as a long-term projects course where students may enroll for several semesters, continuing work on very large-scale projects. Nonetheless, students usually feel pressured to finish their projects within a one-semester time frame. At the end of the semester, when we asked Maria why John mainly coded while she and Jane did content and design, she cited John's speed and the women's prior experience with such a site, adding, "it's just the way the class was set up." Asked what she meant by the class being "set up" that way, she said, "Because of the time pressure. We had to get it all done." Her perception was at odds with the professor's beliefs and observation data about the structure of the courses; that is, students were told explicitly that they did not have to finish projects to earn a grade, but that learning was more important.

\section{FUTURE TRENDS}

Many of the behaviors described in the case study were also displayed by other $\mathrm{T}$ for $\mathrm{C}$ project teams. Students chose or were subtly assigned roles based on their perceptions of experience and apparent beliefs about what kinds of people should make what kinds of contributions. The ways students conceptualize teamwork and the potential contributions of team members have a profound effect on their ability to extend their skills and knowledge beyond what they already know. What students already know is influenced by years of gendered choices, with female students being more likely to have design experience and male students more likely to have programming experience.

When students are allowed to select their roles based on expediency or comfort, it works against the benefits of collaborative and cross-disciplinary learning. While this approach may seem practical and efficient, it does not provide any of the students with a new learning experience, but instead practice of existing skills. Thus, those with less experience fall into this trap, missing out on the opportunity to advance their experience and knowledge about software development and, as a result, continue to remain behind. At the same time, students like John, with technical experience, lose the opportunity to work on skills that they do not already possess, such as client relation skills and content and design.

Without overt and explicit measures implemented and enforced by instructors, other pressures, such as perceived time constraints, a tendency to allow group members to focus on what they already know how to do well, and gendered and disciplinary beliefs about what is appropriate for people of different categories to contribute to a project, male and female students alike can miss out on the opportunity to add to their skills and will instead complete their projects using skills they have already mastered. The multi-disciplinary understanding that comes from having worked in another knowledge domain is a desired, but not acquired, learning gain. 


\section{CONCLUSION}

Both men and women are gendered beings, imposing their beliefs about appropriate behavior for men and women on themselves and on others. The literature on women in IT often portrays women as powerless, passive victims of a male-oriented curriculum within a male-dominated academic culture. This case demonstrates that both men and women can be the agents of oppression, imposing their expectations for behavior on each other and themselves in ways that preclude full participation in a project. Research into gender issues in IT must take into account that both women and men are gendered beings who make gendered choices if we are going to have a better understanding of how to bring to parity the malefemale composition of the IT workforce. Instructors must also make pedagogical choices to impose and enforce learning objectives as part of group assignments. If all students are assessed for particular learning outcomes, the experience gap is less likely to widen.

\section{REFERENCES}

Agogino, A. M., \& Linn, M. (1992). Retaining female engineering students: Will design experiences help? NSF Directions, 5(2), 8-9.

Barker, L. J., Garvin-Doxas, K., \& Jackson, M. J. (2002). Defensive climate in the computer science classroom. SIGCSE Technical Bulletin, 34(1), 9499.

Barker, L. J., Garvin-Doxas, K., \& Roberts, E. (2005, February 23-27). What can computer science learn from a fine arts approach to teaching? In Proceedings of $35^{\text {th }}$ SIGCSE Technical Symposium on Computer Science Education, St. Louis, MO.

Brown, J., Andreae, P., Biddle, R., \& Tempero, E. (1997). Women in introductory computer science: Experience at Victoria University of Wellington. Paper presented at the SIGCSE (ACM).

Bunderson, E. D., \& Christensen, M. E. (1995). An analysis of retention problems for female students in university computer science programs. Journal of Research in Computing in Education, 28(1), 1-18.

Cohoon, J. M., \& Aspray, W. (in press). A critical review of the research on women's participation in postsecondary computing education. In J.M. Cohoon \& W. Aspray (Eds.), Women and information technology: Research on under-representation. Cambridge, MA: MIT Press College Board.

College Board. (2004). AP Program summary report 2004. Retrieved from http://apcentral. collegeboard.com/repository/programsummary report_39028.pdf

Felder, R. M., Felder, G. N., Mauney, M., Hamrin, Jr., C.E., \& Dietz, E. J. (1995). A longitudinal study of engineering student performance and retention. III. Gender differences in student performance and attitudes. Journal of Engineering Education, 84, 151-174.

Fincher, S., Petre, M., \& Clark, M. (2001). Computer science project work: Principles and pragmatics. London: Springer-Verlag.

Haller, C. R. Gallagher, V. J. Weldon, T. L., \& Felder, R. M. (2000). Dynamics of peer education in cooperative learning workgroups. Journal of Engineering Education, 89, 285-293.

IEEE \& ACM Joint Task Force. (2001). Computing curricula 2001. Retrieved from http://www. computer.org/education/cc2001/final/index.htm

Johnson, D. W., \& Johnson, R. T. (1994). Learning together and alone: Cooperative, competitive and individualistic learning. Boston: Allyn \& Bacon.

Margolis, J., \& Fisher, A. (2002). Unlocking the clubhouse: Women in computing. MIT Press.

McDowell, C., Werner, L., Bullock, H., \& Fernald, J. (2002). The effects of pair-programming on performance in an introductory programming class. In Proceedings of the 33 $33^{\text {rd }}$ SIGCSE Technical Symposium on Computer Science Education, Northern Kentucky, KY.

Strenta, A. C., Rogers, E., Russell, A., Matier, M., \& Scott, J. (1994). Choosing and leaving science in 
highly selective institutions. Research in Higher Education, 35(5), 513-547.

Taylor, H. G., \& Mounfield, L. C. (1994). Exploration of the relationship between prior computing experience and gender on success in college computer science. Journal of Educational Computing Research, 11(4), 291-306.

Tinzmann, M. B., Jones, B. F., Fennimore, T. F., Bakker, J., Fine, C., \& Pierce, J. (1990). What is the collaborative classroom? North Central Regional Educational Laboratory. Retrieved from http:// www.ncrel.org/sdrs/areas/rpl_esys/collab.htm

\section{KEY TERMS}

Attrition: When students switch out of a major area of study.

Collaborative Learning: When students work together to learn new material. It contrasts with individual learning, where a student learns without talking to or working with other students.
Cultural and Sociological Context: Specific types of social situations; the ways people behave in social situations are influenced by the cultures, societies, institutions and so forth in which they occur.

Experience Gap: In education, the difference among students in a class in prior knowledge and experience with a subject or activity.

Gender: A set of social categories that shapes how males and females behave and the ways that others treat them based on deeply ingrained expectations about how males and females should respond. In contrast, sex describes biological categories.

Positive Association: A situation where when one element increases, another increases. This does not mean one causes the other, just that they cooccur.

Project-Based Courses: Courses in which students, working individually or in groups, undertake an activity that goes on over a period of time. The outcome is a product, presentation or performance. 